\title{
Finite Element Method modeling of Additive Manufactured Compressor Wheel
}

\author{
Márton Tamás Birosz ${ }^{1}$ - Mátyás Andó ${ }^{1} \cdot$ Sudhanraj Jeganmohan $^{1}$
}

Received: 8 November 2020/Accepted: 20 January 2021/Published online: 13 February 2021

(C) The Author(s) 2021

\begin{abstract}
Designing components is a complex task, which depends on the component function, the raw material, and the production technology. In the case of rotating parts with higher RPM, the creep and orientation are essential material properties. The PLA components made with the material extrusion process are more resistant than VeroWhite (material jetting) and behave similarly to weakly cross-linked elastomers. Also, based on the tensile tests, Young's modulus shows minimal anisotropy. Multilinear isotropic hardening and modified time hardening models are used to create the finite element model. Based on the measurements, the finite element method simulation was identified. The deformation in the compressor wheel during rotation became definable. It was concluded that the strain of the compressor wheel manufactured with material extrusion technology is not significant.
\end{abstract}

Keywords Material extrusion - Material jetting · 3D printing · Creep · Finite element analysis . Additive manufacturing

Márton Tamás Birosz

birosz.marton@gmail.com

Mátyás Andó

am@inf.elte.hu

Sudhanraj Jeganmohan

sudhantribo@gmail.com

1 Savaria Institute of Technology, Eötvös Loránd University, 9700 Szombathely, Hungary

\section{Introduction}

Additive manufacturing technology provides a particular design method for engineers. No restrictions are arising from the machining geometry and movement conditions. On the other hand, each AM technology has its own limitations, like unsupported walls, horizontal bridges, minimum hole, and pin diameter [1-3], which have to be taken into consideration. However, by complying with these simple rules, we can produce a finished product relatively quickly from the virtual model [4]. Furthermore, some geometries would be exceptionally complicated to manufacture with traditional subtractive processes; such geometries can include, for example, form-cores used in casting [5], or complex topology optimized components [6]. In this study, this complex geometry is a unique compressor wheel $[7,8]$. The samples were produced using two specific 3D printing technologies, material jetting (MJ), and material extrusion (ME). Despite the simplicity of ME technology, many influencing factors can affect the quality of the product. Previous studies examined the effects of different layer thicknesses, raster angles, and different infill factor by a tensile test. According to the results, layer thickness has less impact compared to the infill density $[9,10]$. Chaudhari et al. [11] described the possibilities of enhancing the surface roughness of the components by varying settings parameters and using different post-processing methods, and found, for critical geometries, it is worth using soluble support material. Kiendl and Gao [12] investigated the stiffness and strength of the FDM printed PLA components and found the best raster orientation for the particular applications. Rahman et al. [13], like the preceding, have determined the best parameters for the production of a particular component, taking into account a high number of considerations. As it 
is known, 3D printed parts have significant anisotropy [14, 15]. Mitrovic et al. [16] produced test samples in different angular positions. Even the same material but different color filaments were compared, but fortunately, based on the results of the test [17], this is a non-significant influencing factor.

The MJ process is less common, but in theory, it is considered to be more accurate technology. And the surface quality of the produced samples is better than ME technology. Gay et al. [18] measured, that like at the ME samples, the manufacturing orientation of MJ samples affects the mechanical properties. Most importantly, it is advised to print samples parallel with the axes of the global coordinate system and to place them sufficiently far apart. Beltrán [19] found that there was a detectable dimensional difference between pieces that had been printed with different orientations and that the extent of this varies as the size of the component increases. However, it does not reveal a general correlation between them.

Optimizing components by numerical methods is a useful procedure [20]; therefore, the purpose of this article is to determine the material properties, which is the input to the FEM analysis. FEM is commonly used, especially for the structural analysis of complex geometries and materials. Kumar Das and Roy [21] investigated carbon and glass fiber reinforced polymer-based aircraft wing via ANSYS FEM software. With that they were able to create a static structural analysis, a modal analysis and a fatigue life analysis. This technique can be also used for AM parts. James and De La Luz [22] created a simulation for ultrasonic additive manufacturing, to investigate the shear properties. Their results help aerospace and defense industries. The plastic deformation and the time-dependent strain can also be predicted for the component (Fig. 1). In this article a simulation method has been carried out to investigate the creep properties.

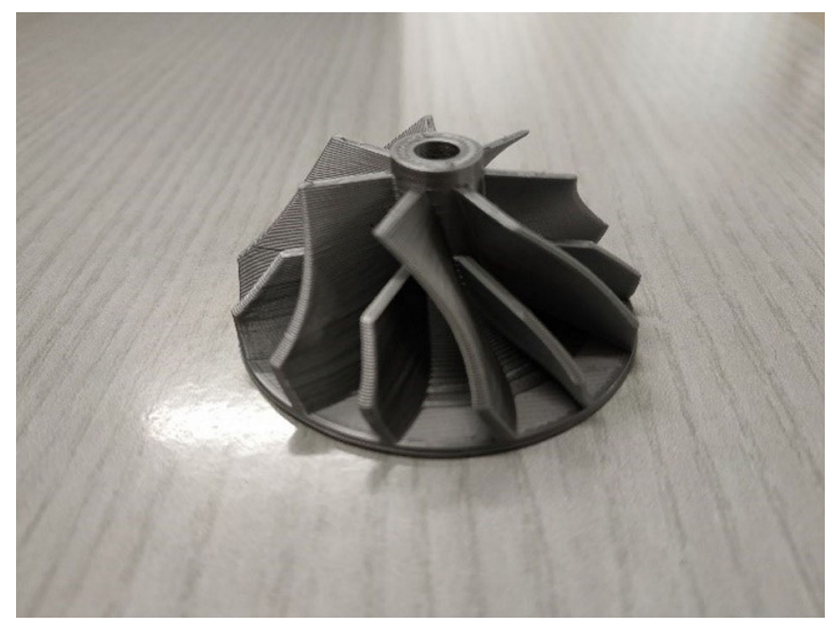

Fig. 1 Compressor wheel

\section{Materials and Methods}

First, tensile tests are performed to define the tensile strength, tensile modulus, and Poisson's ratio. Based on the literature, it is possible to determine the appropriate printing parameters and eliminate the harmful effects during production. The only influencing factor was the printing orientation, since the adhesion force that binds the layers differs from the inner molecular cohesive force of the material. The parts printed in different orientations have different mechanical properties.

The obtained results from the tests are used during design to withstand maximum stress. Polymers are typically not designed to a maximum stress, but to withstand specific deformation [23]. This is especially true for turbine blades, where the metal variants are facing trouble due to creeping. Therefore, the creep properties of the manufactured parts are also examined [24].

\section{Materials and Printing Parameters}

The test specimens have been printed with the same setup parameters under the same conditions. Polylactide (PLA) had been used for ME prints. It is the most common 3D printing material, due to its simple printability and biodegradability. For the production of ME samples, $\varnothing 1.75 \mathrm{~mm}$ diameter filament was used, which is a standard diameter for filament. The model was created in Inventor2020 CAD software, and it was prepared for printing by Cura 3.4.1 Slicer program. Anet A8 printer was used with $220{ }^{\circ} \mathrm{C}$ printing temperature and $60{ }^{\circ} \mathrm{C}$ as a build plate temperature. Fan cooling, $0.2 \mathrm{~mm}$ layer thickness, and $100 \%$ infill as machining parameters.

For MJ, the Objet30 printer and the VeroWhite resin material distributed by the machine manufacturer were used. $100 \%$ infill and the matte surface were set as parameters.

\section{Testing and Characterization}

The tensile test was performed on a UTM Machine, as per ISO 527-1:2012 standard (using extensometers to measure the deformation in both dimensions of the cross section), with a measured geometry chosen from ISO 20,753:2019 standard. The results were evaluated using textXpert software.

The three-point bending test was made. For this test, the same machine Zwick Roell Z100 was used with the supplementary bending heads. The measurement was as per ISO 178:2011 standard. The specimen geometry as per the ISO 20,753:2019 standard in Fig. 3 was used.

The geometry of the sample used for the tensile test was also used for the creep test. The machining parameters of 
the pieces were left unchanged. A long-term creep test was made, with different loads, and the strain was measured on each sample at specific intervals. Loads of $0.625 \mathrm{MPa}$ $(2.5 \mathrm{~kg}), 1.125 \mathrm{MPa}(4.5 \mathrm{~kg})$, and 1,625 MPa $(6.5 \mathrm{~kg})$ were used, and the results were measured for one year at a constant temperature of $22^{\circ} \mathrm{C}$.

\section{Specimen}

Three specimens with four specific angles were developed at $0^{\circ}, 15^{\circ}, 30^{\circ}$, and $45^{\circ}$, as shown in Fig. 2. For each orientation, there had been three samples developed.

It was unable to develop rotated tensile test pieces with the Objet30 machine because the print head movement causes the pieces to fall during printing. However, bending test specimens were able to be printed with different orientations (Fig. 3). The angular positions are the same as the tensile pieces, but it has been made only one sample for each orientation.

\section{Results and Discussion}

\section{Mechanical Properties-Tensile Test}

The tensile test results of the specimens placed parallel with the build platform (i.e. $0^{\circ}$ orientation) (Fig. 4) show that the behavior of the material as a polymer cannot be described in a linear elastic model.

From a design point of view, the relevant data (Table 1) are tensile strength $(\sigma)$, the initial tensile modulus $\left(\mathrm{E}_{\mathrm{i}}\right)$, and approximate tensile modulus $\left(\mathrm{E}_{\mathrm{a}}\right)$. Based on the standard, the initial tensile modulus $\left(\mathrm{E}_{\mathrm{i}}\right)$ is the initial slope of the material to prolong $0.25 \%$ on the curve (Fig. 4 ), as there is no clear yield point. On the other hand, when using FEM, it is defined as a linear material model for nonlinear elastic material. For this, the approximate tensile modulus $\left(\mathrm{E}_{\mathrm{a}}\right)$ can be defined by replacing the section between the unloaded

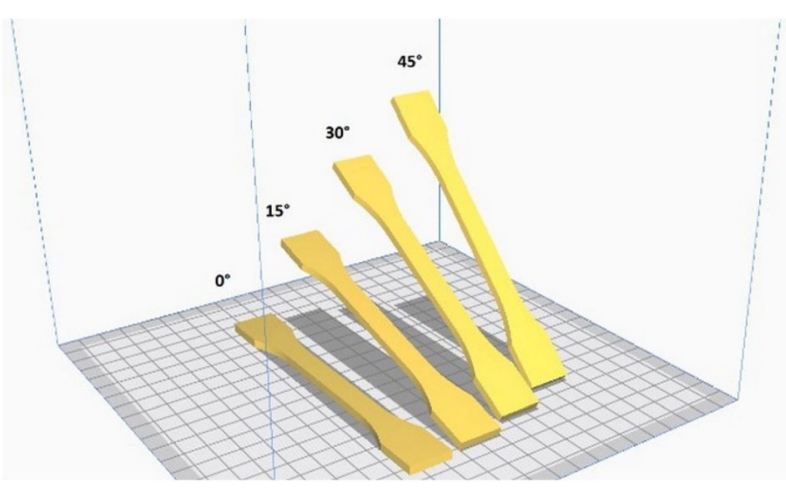

Fig. 2 Tensile test specimens printing orientations

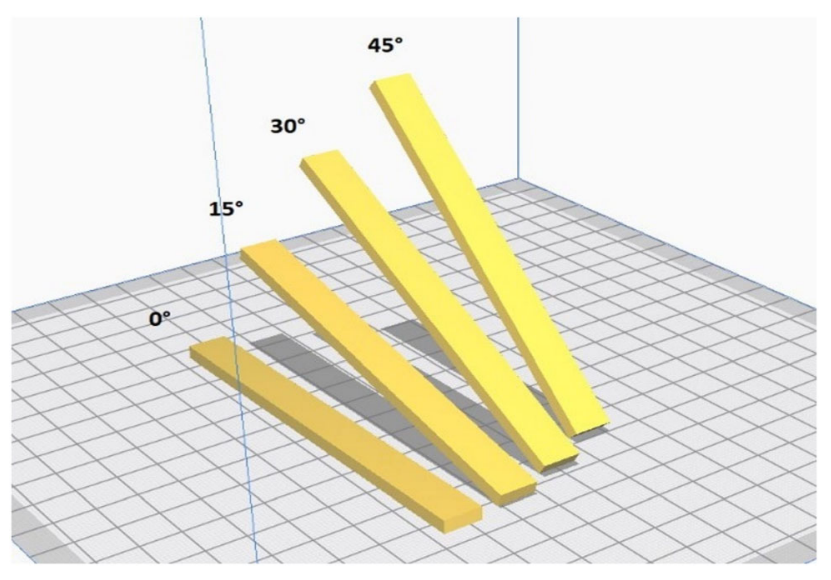

Fig. 3 Bending test specimens printing orientation

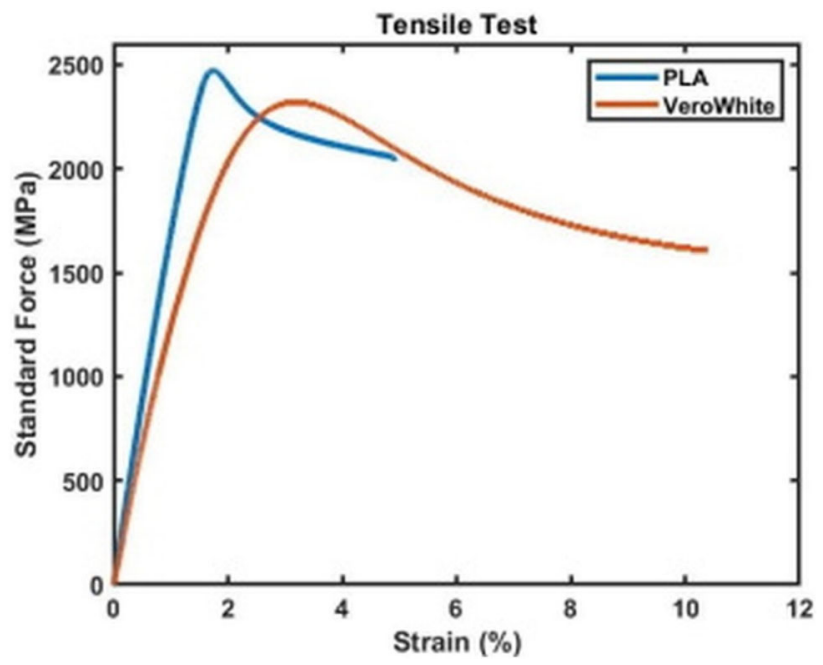

Fig. 4 Tensile test of specimens printed parallel with the build platform

state and the maximum tensile strength with a straight line. The $E_{a}$ simplifies the calculations required for designing.

Comparing the ME specimens rotated along the X-axis, it is stated that the viscoelastic behavior (beginning of the tensile curve) differs negligible, only the maximum tensile strength showed changes (Fig. 5). The adhesion force that binds the layers together is weaker than the cohesion force in the layer. As the load increases, initially, the layers begin to separate, which create the cracks. If the orientation angle is high, the crack propagation became larger (weaker crosssection). Therefore, if possible, the components should be optimized. The direction of the layers should be parallel with the load.

\section{Creep Performance}

The creep test results are shown in Figs. 6 and 7. The tests show that the characteristics of ME samples are most 
Table 1 Tensile properties of the PLA and VeroWhite

\begin{tabular}{lcc}
\hline & PLA & VeroWhite \\
\hline $\begin{array}{l}\text { Tensile strength } \\
\sigma[\mathrm{MPa}]\end{array}$ & 60.6 & 55.9 \\
$\begin{array}{l}\text { Initial modulus } \\
\mathrm{E}_{\mathrm{i}}[\mathrm{MPa}]\end{array}$ & 2190 & 1690 \\
Approximate modulus $\mathrm{E}_{\mathrm{a}}[\mathrm{MPa}]$ & 1359 & 766 \\
Poisson's ratio & 0.32 & 0.38
\end{tabular}

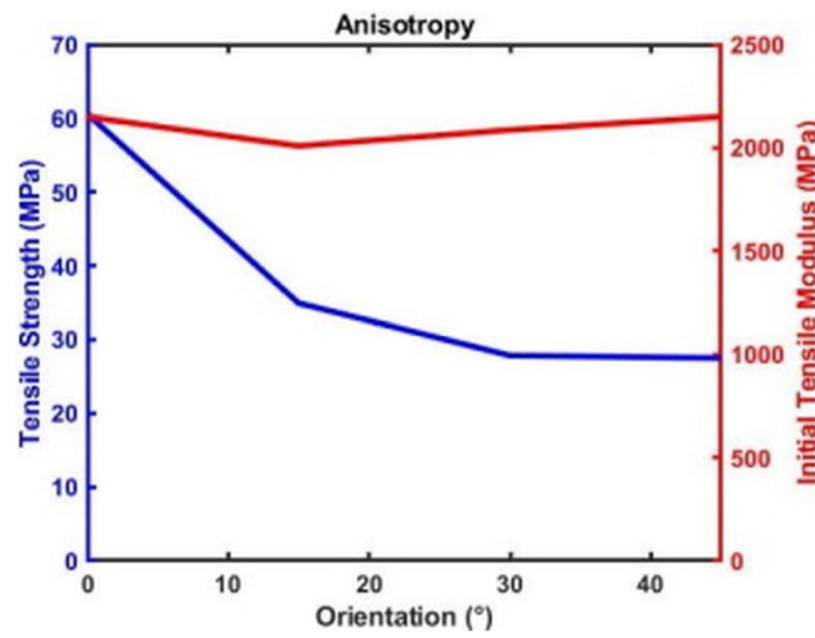

Fig. 5 Anisotropy of PLA due to print orientation

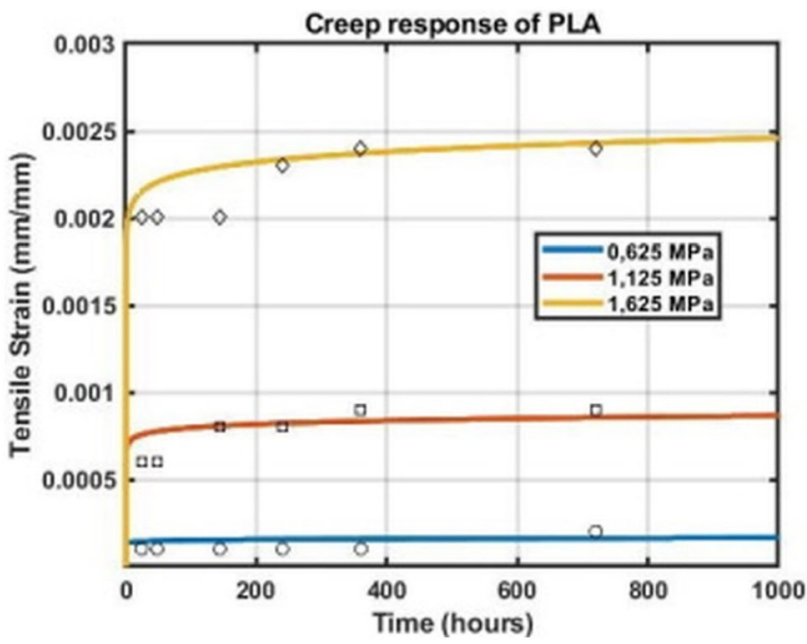

Fig. 6 Creep response of PLA

similar to the weakly cross-linked elastomer, i.e., at low loads, the creep curve is held to a constant limit. Based on the results of MJ samples, it is considered more as amorphous thermo-plastic. Since the slope of the creeping curve is gradually increasing in a positive direction (Fig. 7), so a residual slip is possible. It is possible to determine the

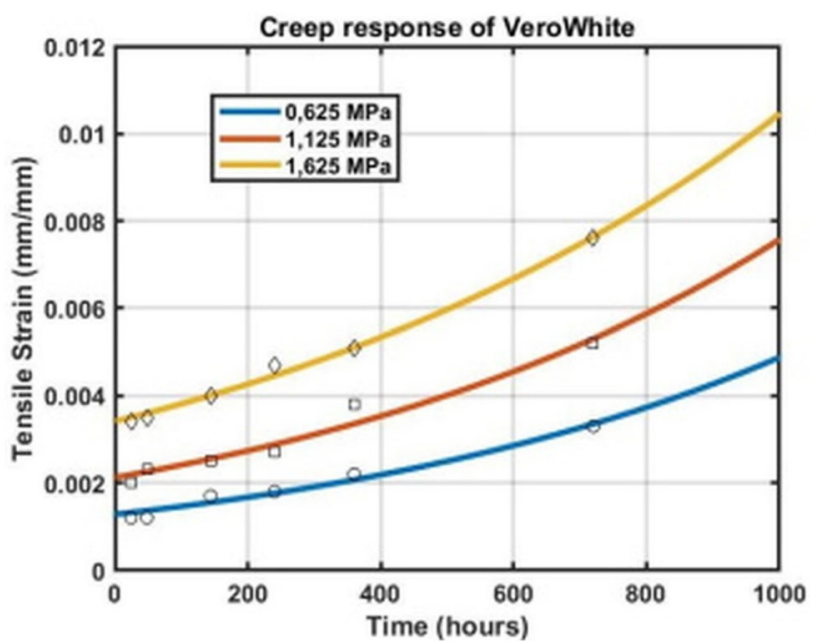

Fig. 7 Creep response of VeroWhite

deformation at a given time (for each load), which can help at designing parts of long-cycle machines.

Modified time hardening model was used to describe the creep (Eq. 1):

$\varepsilon_{c r}=\frac{C_{1} \sigma^{C_{2}} t^{C_{3}+1} e^{-\frac{C_{4}}{T}}}{C_{3}+1}$

Since there are no measurement results that showed the effect of temperature. The temperature-dependent part was removed from the equation. The modified equation: (Eq. 2).

$\varepsilon_{c r}=\frac{C_{1} \sigma^{C_{2}} t^{C_{3}+1}}{C_{3}+1}$

To calculate $\mathrm{C}_{1-3}$ constants, Excel Solver was used to fit the correct curves to the measurement data. The parameters are the following:

- $C_{1}=1.3 \times 10^{-5}$,

- $C_{2}=2.8387$,

- $C_{3}=-0.9638$,

- $C_{4}=0$,

the regression was 0.985 in this case.

It is clear from the measurement results that the printed parts exposed to creep from VeroWhite material are not worth producing. Therefore, it is decided to focus on PLA raw material.

\section{Bending properties}

The bending test results are shown in Table 2 .

Reference papers $[12,13]$ found that orientation had a negligible effect on the properties in the case of VeroWhite. The bending test has also confirmed that MJ technology mostly gives isotropic behavior. 
Table 2 VeroWhite bending results

\begin{tabular}{lll}
\hline & Bending strength $-\sigma_{\mathrm{b}}[\mathrm{MPa}]$ & Bending modulus- $\mathrm{E}_{\mathrm{b}}[\mathrm{MPa}]$ \\
\hline $0^{\circ}$ & 56 & 2039 \\
$15^{\circ}$ & 58 & 2012 \\
$30^{\circ}$ & 56 & 2040 \\
$45^{\circ}$ & 54 & 2019 \\
\hline
\end{tabular}

\section{FEM Analysis}

Due to the complexity of the compressor wheel, it is quite challenging to determine the deformations resulting from the load by manual calculations, so ANSYS 2019 R3 FEM software was used. It is possible to set multilinear isotropic hardening (Fig. 8) to define the plasticity of the material. This is necessary to detect residual strain and large deformations where the linear model does not work.

Also, it is possible to set the parameters to calculate creep. Modified time hardening model based on the values generated using excel was used in ANSYS, where $\mathrm{C}_{4}$ is set to 0 .

The simulations were made with the measured test specimen geometry. Figure 9 shows that there is some difference between the numeric solution and the result of the simulation.

For example, the measured strain on the 30th day was 0.0024 . From the simulation, the creep strain over 30 days was 0.00215 for the specimen loaded with $65 \mathrm{~N}$. And the numerical calculation result was 0.00243 creep strain over this time. It is an $11.5 \%$ error. The element size for the mesh was $2 \mathrm{~mm}$. The denser mesh did not lead to more accurate results, so the simulation is less sensitive to the

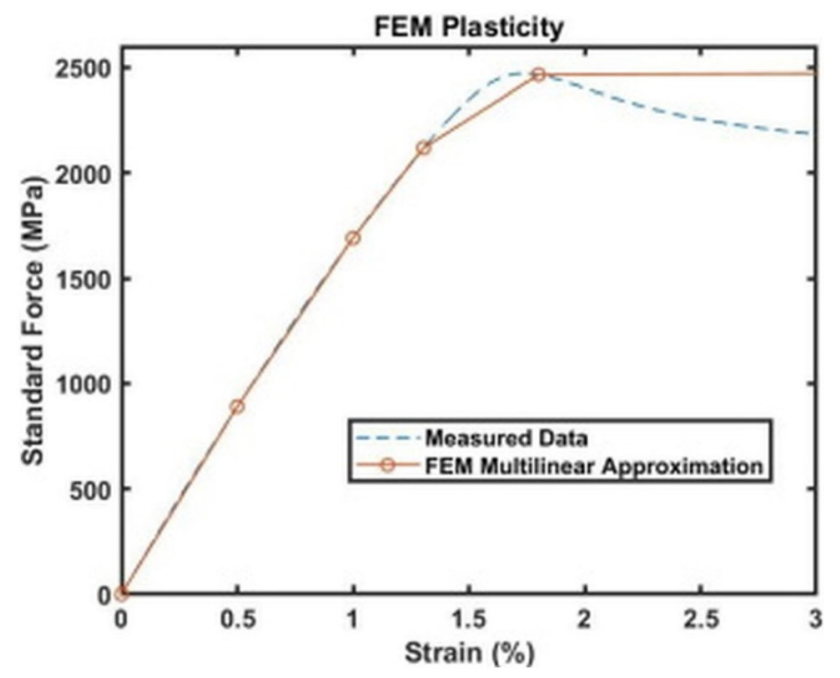

Fig. 8 Multilinear isotropic hardening of PLA

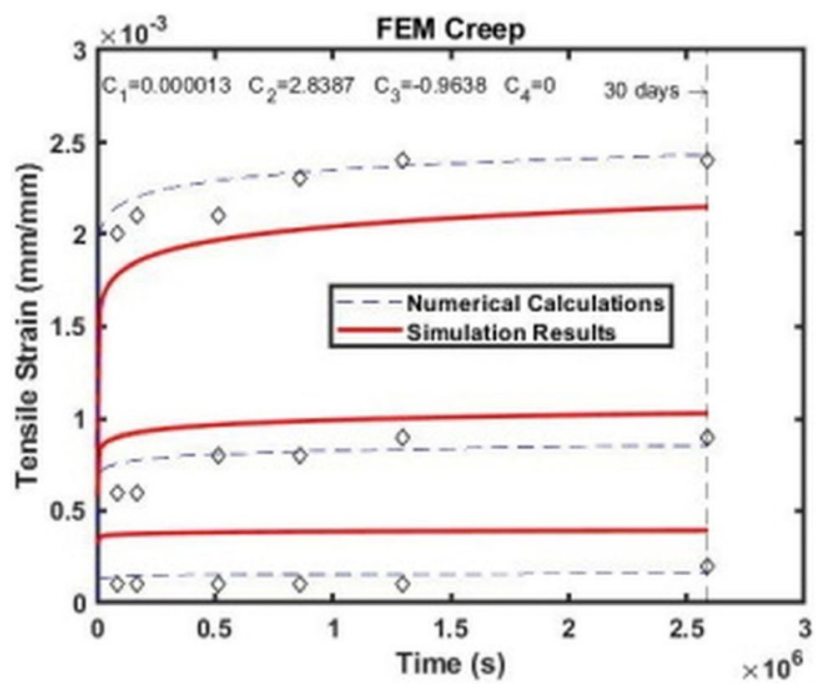

Fig. 9 FEM simulation of creep

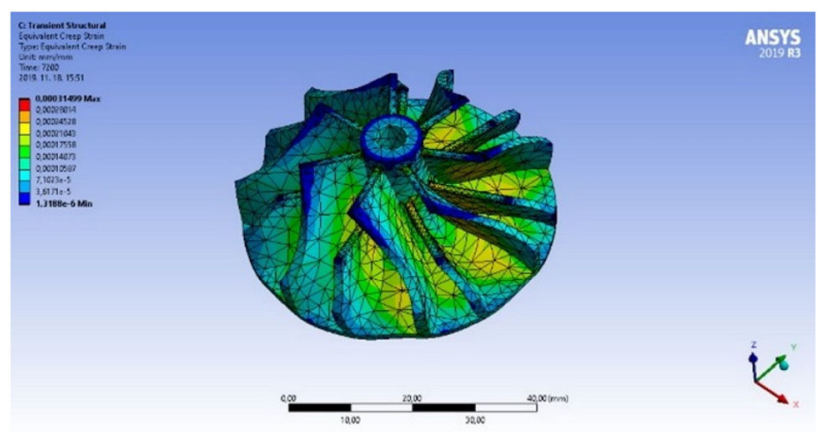

Fig. 10 Equivalent Creep Strain of the wheel

mesh. The difference between the result of the measurement and the result of the simulation is $10-15 \%$.

Next, the compressor wheel simulation was carried out with the tested parameters. For mesh, a $2 \mathrm{~mm}$ element size was chosen, similar to those used for the tensile specimens. The hole of the wheel was supported with cylindrical support, which ensures tangential displacement. This rotates at a given rotational velocity around the axis of the cylindrical support, while the compressor blades are loaded with a defined air pressure (Fig. 10).

The results showed that the elongation could be only $0.03 \%$, even in such unrealistic conditions.

\section{Conclusion}

In the case of printed parts, traditional measurements and modeling techniques were used with certain additions. 
- The material extrusion samples have a spatial anisotropy, due to the inter-layer adhesive bonding. This mostly affects only the maximum tensile strength but has minimal impact on the flexural modulus.

- In the case of creeping properties, the material extrusion and material jetting technologies behave entirely differently. For long-term service, it is worth to choose PLA, even though it is anisotropic behavior.

- Although the result of creep in FEM modeling differs from the measured values, the deviation remains within the acceptable range. So that complex geometry can be tested in this method.

Acknowledgements Authors express their thanks to NKFIH for the support provided by funding the project (ED_18-1-2019-0030)

Funding Open access funding provided by Eötvös Loránd University. Project no. ED_18-1-2019-0030 (application-specific highly reliable IT solutions) has been implemented with the support provided from the National Research, Development and Innovation Fund of Hungary, financed under the Thematic Excellence Programme funding scheme.

Open Access This article is licensed under a Creative Commons Attribution 4.0 International License, which permits use, sharing, adaptation, distribution and reproduction in any medium or format, as long as you give appropriate credit to the original author(s) and the source, provide a link to the Creative Commons licence, and indicate if changes were made. The images or other third party material in this article are included in the article's Creative Commons licence, unless indicated otherwise in a credit line to the material. If material is not included in the article's Creative Commons licence and your intended use is not permitted by statutory regulation or exceeds the permitted use, you will need to obtain permission directly from the copyright holder. To view a copy of this licence, visit http://creativecommons. org/licenses/by/4.0/.

\section{References}

1. B. Redwood, F. Schöffer, B. Garret, The 3D printing handbook, the netherlands: 3D Hubs, 2017.

2. K.G. Swift, J.D. Booker, Manufacturing process selection handbook. Butterworth-Heinemann (2013). https://doi.org/10. 1016/C2011-0-07343-X

3. S. Kalpakjian, S.R. Schmid, Manufacturing Engineering and Techonology (Pearson Education South Asia Pte Ltd., Singapore, 2009).

4. A.K. Matta, D. Ranga Raju, K.N.S. Suman, The integration of $\mathrm{CAD} / \mathrm{CAM}$ and rapid prototyping in product development: a review. Mater Today Proc 2, 3438-3445 (2015). https://doi.org/ 10.1016/j.matpr.2015.07.319

5. P. Jain, A.M. Kuthe, Feasibility study of manufacturing using rapid prototyping: FDM approach. Procedia Eng 63, 4-11 (2013). https://doi.org/10.1016/j.proeng.2013.08.275

6. A. Garaigordobil, R. Ansola, E. Veguería, I. Fernandez, Overhang constraint for topology optimization of self-supported compliant mechanisms considering additive manufacturing. CAD
Comput. Aided Des. (2019). https://doi.org/10.1016/j.cad. 2018.12.006

7. K. Ohri, K. Shoghi (2012) Compressor wheel low cycle fatigue calculations for off highway applications - An approach to accurately calculate application duty cycle, Inst. Mech. Eng. 10th Int. Conf. Turbochargers Turbocharging, https://doi.org/ 10.1533/9780857096135.2b.97.

8. B. Zhao, L. Hu, Q. Zhao, X. Zhou, Investigation of variable orifice plate design for centrifugal compressor low-end performance improvement. Aerosp. Sci. Technol. (2020). https://doi. org/10.1016/j.ast.2019.105585

9. G. Jothibabu, S.K. Gurunathan, Surrogate based sensitivity analysis of part strength due to process parameters in fused deposition modelling. Procedia Comput. Sci. 133, 772-778 (2018). https://doi.org/10.1016/j.procs.2018.07.120

10. S. Wang, Y. Ma, Z. Deng, S. Zhang, J. Cai, Effects of fused deposition modeling process parameters on tensile, dynamic mechanical properties of 3D printed polylactic acid materials. Polym. Test. (2020). https://doi.org/10.1016/j.polymertesting. 2020.106483

11. M. Chaudhari, B.F. Jogi, R.S. Pawade, Comparative Study of Part Characteristics Built Using Additive Manufacturing (FDM). Procedia Manuf 20, 73-78 (2018). https://doi.org/10.1016/j. promfg.2018.02.010

12. J. Kiendl, C. Gao, Controlling toughness and strength of FDM 3D-printed PLA components through the raster layup. Compos. Part B Eng. 180, 107562 (2020). https://doi.org/10.1016/j. compositesb.2019.107562

13. H. Rahman, T.D. John, M. Sivadasan, N.K. Singh, Investigation on the scale factor applicable to ABS based FDM additive manufacturing. Mater. Today Proc. 5, 1640-1648 (2018). https://doi.org/10.1016/j.matpr.2017.11.258

14. P. Kumar Mishra, P. Senthil, Prediction of in-plane stiffness of multi-material 3D printed laminate parts fabricated by FDM process using CLT and its mechanical behaviour under tensile load. Mater Today Commun (2020). https://doi.org/10.1016/ j.mtcomm.2020.100955

15. T.D. Ngo, A. Kashani, G. Imbalzano, K.T.Q. Nguyen, D. Hui, Additive manufacturing (3D printing): a review of materials, methods, applications and challenges. Compos. Part B Eng. 143, 172-196 (2018). https://doi.org/10.1016/j.compositesb. 2018.02.012

16. R. Mitrović, Z. Mišković, M. Ristivojević, A. Dimić, J. Danko, J. Bucha, T. Milesich, Statistical correlation between the printing angle and stress and strain of 3D printed models. Procedia Struct Integr (2018). https://doi.org/10.1016/j.prostr.2018.12.079

17. A.P. Valerga, M. Batista, R. Puyana, A. Sambruno, C. Wendt, M. Marcos, Preliminary study of PLA wire colour effects on geometric characteristics of parts manufactured by FDM. Procedia Manuf. 13, 924-931 (2017). https://doi.org/10.1016/j.promfg. 2017.09.161

18. P. Gay, D. Blanco, F. Pelayo, A. Noriega, P. Fernández, Analysis of factors influencing the mechanical properties of flat polyjet manufactured parts. Procedia Eng (2015). https://doi.org/10. 1016/j.proeng.2015.12.481

19. N. Beltrán, F. Carriles, B.J. Álvarez, D. Blanco, J.C. Rico, Characterization of factors influencing dimensional and geometric errors in polyjet manufacturing of cylindrical features. Procedia Eng (2015). https://doi.org/10.1016/j.proeng.2015.12.480

20. R. Patel, S.K. Dubey, K.K. Pathak, Analysis of infilled beams using method of initial functions and comparison with FEM. Eng. Sci. Technol. Int. J. (2014). https://doi.org/10.1016/j. jestch.2014.05.001

21. S. Kumar Das, S. Roy, Finite element analysis of aircraft wing using carbon fiber reinforced polymer and glass fiber reinforced 
polymer. IOP Conf Ser Mater Sci Eng (2018). https://doi.org/ 10.1088/1757-899X/402/1/012077

22. S. James, L. De La Luz, Finite element analysis and simulation study of CFRP/Ti stacks using ultrasonic additive manufacturing. Int J Adv Manuf Technol 104, 4421-4431 (2019). https://doi.org/10.1007/s00170-019-04228-6

23. G. Bodor, L.M. Vas, Polimer Anyagtudomány (Budapesti Müszaki Egyetem, Budapest, 1999).
24. T.A. Osswald, G. Menges, T.A. Osswald, G. Menges, Material science of polymers for engineers. Mater Sci Polym Eng (2012). https://doi.org/10.3139/9781569905241.fm

Publisher's Note Springer Nature remains neutral with regard to jurisdictional claims in published maps and institutional affiliations. 